\title{
Legislación procesal familiar en el Perú
}

Nelson Reyes Ríos

\section{Necesidad de una legislación familiar especial en el Perú. Código de Familia: sustantivo y procesal}

Por nuestra parte, tenemos definida una firme posición sobre la necesidad de promulgar en el Perú un Código de Familia integral, tanto en su aspecto sustantivo así como de orden procesal. Así se ha sostenido en nuestro trabajo de tesis doctoral ${ }^{1}$, en 1974, al tratar sobre el aspecto de la autonomía del Derecho familiar. En dicha oportunidad se comentó el estudio del desaparecido y recordado maestro argentino, Enrique Díaz de Guijarro ${ }^{2}$, quien afirmaba que «dos manifestaciones originales han aparecido durante el corriente siglo, en orden a la regulación de la familia: la inclusión de normas sobre familia en las Constituciones políticas de los Estados, y el cisma del Derecho civil, con la autonomía de las reglas sobre familia. Esto significa que la corriente actual se dirige hacia la formación de un cuerpo legal sobre Derecho de familia, llámese Código de Familia, Ley sobre Familia, o que se tome otras denominaciones, como Estatuto de Familia, en donde se contemplan en forma orgánica y sistemática, normas con la concepción de una nueva organización familiar de acuerdo a los adelantos actuales y a las necesidades sociales imperantes en nuestros tiempos". En base a estas y otras consideraciones, fundamentalmente de orden prioritario y social, en dicho trabajo formulamos la siguiente conclusión: «Quinta: entre otras, como modernas concepciones del Derecho de familia, se consideran: la autonomía en su regulación, debido a que contiene normas de orden público en

\footnotetext{
Reyes Rios, Nelson: Evolución del Derecho de familia y las modernas concepciones sobre matrimonio y filiación, tesis (1974).

- DIAZ DE GullarRo, Enrique: Derecho de familia.
} 
grado mayor que otras ramas del Derecho, que no rigen en igual forma para las otras ramas, específicamente del Derecho privado.» En trabajos posteriores también incidimos sobre este tema, precisando la necesidad de elaborar no solamente un Código de Familia, con normas de carácter sustantivo, sino proponiendo la inclusión de normas procesales, y al conjunto denominarlo Legislación familiar en el Perú.

Así, se publicó en 1990 un artículo que preparamos ${ }^{3}$ para la revista Ius Et Praxis, editada por la Facultad de Derecho de la Universidad de Lima, con el título de "Legislación familiar autónoma: el Código Familiar para el estado de Hidalgo» (México), en donde señalamos el avance, posiblemente lento pero seguro, de las legislaciones autónomas de familia a nivel de legislación comparada, en su origen posiblemente consideradas como un movimiento político, para luego extenderse con un carácter de necesidad y existencia real de la familia. Así, se puede mencionar el Código de Familia de Rusia (1918), con sus sucesivas reformas; el de Yugoslavia (1946); Bulgaria (1949); Checoslovaquia (1959); Rumania; Hungría; Alemania del Este y Cuba (1975). En la actualidad muchas de estas legislaciones han tenido que ser replanteadas, debido fundamentalmente a los acontecimientos sociopolíticos y económicos que se han producido, como la desintegración de las repúblicas que conformaban la Unión Soviética, y el derrumbe del muro que dividía Alemania, entre otros. En América, esta corriente de legislación autónoma de la familia ha dejado de tener un carácter puramente político, para convertirse en un medio necesario de protección de la primera célula fundamental de la sociedad, como es la familia. Así, se tiene el Código de Familia de Bolivia (1972), de Costa Rica (1973), el Código Familiar para el estado de Hidalgo en México en 1983, al que se agrega con posterioridad el Código de Familia de El Salvador de 1993 y el de Panamá de 1994.

Con estos antecedentes, decíamos, en el trabajo en referencia: "por nuestra parte hemos tomado la firme posición de sostener la necesidad de contar con una legislación familiar de carácter integral, proteccionista de la familia como célula básica de la sociedad e institución fundamental de las naciones». De igual manera, en el segundo Congreso $\mathrm{Na}$ cional de Derecho Civil y Comercial, organizado por la Universidad Nacional Mayor de San Marcos de Lima (Perú) en noviembre de 1995, hemos presentado un trabajo con el título de "Modernas concepciones

3 Reyes RIOS, Nelson: "Legislación familiar autónoma: el Código Familiar para el estado de Hidalgo" (México), revista Its et Praxis, Facultad de Derecho de la Universidad de Lima, n.o 15. 
en el Derecho familiar", considerando como temas nuevos -entre otrosla sistematización del Derecho familiar y la necesidad de promover la diligencia de preconciliación en los conflictos familiares. En materia de sistematización del Derecho familiar, reiteramos nuestra posición en favor de la codificación familiar, indicando: «resulta indispensable, y quizás el punto de partida más importante para una nueva concepción jurídica familiar en el Perú, el tema de su autonomía, basada en el sustento de su carácter de orden público." Para estos efectos utilizamos como fundamento dos criterios básicos: Primero, el principio de la voluntariedad en los actos jurídicos familiares, y segundo, el de la legitimidad de intereses. Es innegable que la voluntariedad está y debe estar presente en todos los actos de la familia, pero una voluntad con un adecuado control en función social, y con una legitimidad de intereses de carácter general, antes que de orden particular. Es por eso que se consagra en la Declaración Universal de los Derechos Humanos (aprobada por la Asamblea General de las Naciones Unidas en 1948, ratificada por el Perú y, por lo tanto, parte integrante de la legislación interna), que la familia constituye célula fundamental de la sociedad. Cuando propiciamos una legislación autónoma del Derecho familiar, como ya se indicó en líneas anteriores, nos referimos a la legislación integral de carácter sustantivo y procesal. Pero, como complemento de dicha atención legislativa deben necesariamente implementarse los Juzgados y Salas de Familia en el ámbito jurisdiccional, con magistrados debidamente especializados.

Por su parte, el propulsor del Código Familiar de Hidalgo (México), profesor Julián Guitrón Fuentevilla Código Familiar", precisa: «Para su completa reglamentación, es indispensable promulgar un nuevo ordenamiento familiar, moderno, sistematizado, enmarcado de la realidad social y enfocado a resolver la actual problemática familiar. Conscientes de que la familia en cada parte de la república-refiriéndose a México, que por coincidencia resulta similar a muchas naciones de América, y por supuesto al Perú- es diferente, se sugiere la posibilidad de legislar en el Distrito Federal, primero, y después en todo el país. Adaptar en cada estado sus usos, costumbres y prácticas sociales, dándoles valor legal. La justicia familiar clama por un cuerpo de leyes especializado. Mayor estabilidad y permanencia se logrará con esta clase de legislación. Incrementar el respeto entre sus miembros. Reducir el machismo. Más posibilidades para vivir mejor. Tener el número adecuado de hijos, debidamente protegidos. Crear un instru- 
mento jurídico propio para lograr el verdadero equilibrio familiar, el cual repercutirá en beneficio de la sociedad y del Estado. Una legislación familiar de esta naturaleza deberá poner las bases de una nueva sociedad, derribar mitos, crear nuevas estructuras económicas, culturales, sociales y familiares para proteger a los niños, los inválidos, y los ancianos."

En el Código de Familia de Panamás, promulgado por ley número 3, del 17 de mayo de 1994, al hacerse una breve reseña histórica, se anota que, uen el documento de CONAFA (Comisión Nacional para la Familia Panameña), donde se formulan y recomiendan propuestas con miras a que el Estado establezca las bases para la revisión, actualización y elaboración de una nueva y moderna política social, destinada a ofrecer una efectiva protección a la familia panameña y sus miembros, menores, mujer, tercera edad, y descapacitados, se recomienda la elaboración del Código de la Familia».

Abundando con el criterio codificador de la familia, la doctora Carmen Meza Ingar ${ }^{6}$, en su obra, Más allá de la igualdad. Los derechos de la mujer en el año 2000, señala: "por ser la familia una institución fundamental, distintos foros internacionales se han pronunciado por la urgencia de aprobar en cada país un Código de Familia. En la XXI Convención Internacional de la Federación Internacional de Abogados (FIDA), realizada en 1982, la doctora Sonia Sgambatti planteó como meta el Código de Familia, para que se difundan y se conozcan todas las normas que regulan la vida familiar y ciudadana”.

\section{Justificación para una legislación procesal familiar en el Perú}

Como se indicó anteriormente, la legislación familiar procesal va unida a la codificación sustantiva -el Código de Familia-, formando un solo cuerpo legislativo familiar. Sin embargo -sólo con carácter didáctico-, resulta conveniente hacer una breve referencia sobre la forma como se ha procedido en el Perú en esta materia. Así tenemos que, promulgado en la época republicana el primer Código Civil de 1852, se sucedieron en materia procesal, de manera orgánica, primero el llamado Código de Enjuiciamientos Civiles y posteriormente el -derogado últimamente-, Código de Procedimientos Civiles de 1912, cuyo cuerpo legislativo lógicamente respondía a los lineamientos y principios filosóficos que orientaban el referido código sustantivo de 1852. Con el transcurso del tiem-

Código de Familia de Panamá, edición oficial, 1994.

MeZa InGAR, Carmen: Más allá de la igualdad. Los derechos de la mujer en el año 2000. 
po éste ha tenido que ser modificado en su estructura normativa en muchas oportunidades. Con la promulgación de los códigos sustantivos de 1936 y 1984 (este último, vigente en la actualidad desde el 14 de noviembre de 1984 y promulgado mediante decreto legislativo 295 del 24 de julio de 1984), legislativamente se ha producido en el Perú un desfase en materia procesal, por cuanto aun con dichos códigos sustantivos se siguió aplicando el Código de Procedimientos Civiles de 1912, con la consecuencia prevista de que no se adecuaba en muchas de sus disposiciones a los planteamientos de las modernas concepciones del Derecho procesal. Con el objeto de atenuar en parte esta falta de coherencia legislativa, se han producido innumerables reformas y modificaciones del Código de Procedimientos Civiles, como se dijo, siendo necesario contar con una ley especial de adaptación procesal para el Código Civil de 1984 en todas las materias y lógicamente en el Derecho de familia (en donde las modificaciones que ha sufrido el Código Civil de 1936 por el nuevo de 1984 han sido muy profundas), mediante la promulgación del decreto legislativo 310 -para entrar en vigencia también el 14 de noviembre de 1984-, en cuyo artículo primero se indicaba: "Incorpórase al Código de Procedimientos Civiles las normas procesales que siguen, relativas a la aplicación de las disposiciones del Código Civil citadas en éstas», cuyo esquema ha sido el siguiente: sobre Derecho de las personas. principio de la persona, derecho de la persona, desaparición, declaración de ausencia, declaración de muerte presunta, asociación, fundación; sobre Derecho de familia: esponsales, matrimonio, separación de cuerpos y divorcio, alimentos; y sobre fuentes de las obligaciones: responsabilidad extracontractual.

Pero además resulta necesario que se tome en cuenta que en materia familiar las normas procesales contienen reglas de carácter especial, a veces de naturaleza diferente a los procesos comunes, a las que en conjunto se les conoce con el nombre de causas matrimoniales, por ejemplo: el valor del allanamiento en los procesos de divorcio y de invalidación del matrimonio; la confesión o declaración de parte -y declaración de parientes cercanos en muchos casos-. Lo mismo sucede en otros aspectos, como el principio de la cosa juzgada en materia familiar, como señala el autor Jorge Edgardo Crespi ${ }^{7}$ cuando afirma que, con el objeto de "una solución eficiente, coherente y satisfactoria en el orden jurídico para la cuestión de los efectos de la cosa juzgada en el Derecho de familia, debe observarse ciertos requerimientos o exigencias fundamentales».

Crespl, Jorge Edgardo: La cosa juzgada en el Derecho de familia. 
Comentando sobre estas ideas, en el VII Congreso Mundial sobre Derecho de Familia, llevado a cabo en El Salvador en 1992, se le ha dedicado un tema de estudio referido al Derecho procesal familiar, con mención de temas especiales, como el proceso familiar y sus características, entre otros. Estas ponencias fueron sustentadas, primero, por nuestra siempre reconocida amiga y estudiosa de estos temas, doctora Aída Kemelmajer de Carlucci, de la delegación argentina, quien afirmó que «en el primer Congreso Mundial sobre Derecho Familiar y Derecho Civil, que tuvo lugar en Acapulco, México, en 1978, así como en el Congreso Hispanoamericano de Profesores de Derecho de Familia, reunido en marzo de 1983, en Salta, Argentina, en ambos se coincidió en que la existencia de los tribunales especializados, técnicamente asesorados, contribuye a garantizar y consolidar la convivencia familiar y a resolver con mayor justicia y eficacia los conflictos familiares, pero su eficaz funcionamiento requiere normas particulares de procedimientos, regidos, entre otros, por los principios de inmediación, celeridad, actuación de oficio, concertación, preclusión relativa y amplitud de medios probatorios». A los que podríamos agregar el criterio de informalidad o formalidad flexible, no rígida, ya que se trata de resolver problemas vinculados a conductas humanas, para los cuales no resulta apropiado el criterio patrimonial o cuasipatrimonial.

La segunda ponencia que se presentó en el aludido certamen de carácter mundial, fue el trabajo de la doctora Dora Eusebio Goutreaux ${ }^{8}$, de la delegación de Santo Domingo, quien señaló: «antes de hablar de proceso familiar repensemos en su objeto de estudio, la familia, el grupo social al que va destinado este esfuerzo jurídico; lógicamente deberíamos analizar un tanto rápidamente su perfil. La ventilación de los asuntos de familia tiene sus propias implicaciones. Los asuntos jurídicos más delicados se presentan alrededor de los conflictos no entre particulares, sino entre allegados. Los sentimientos humanos afloran, la pasión, el odio, el amor, el resentimiento, los roles de conducta aprendidos y repetidos, odiados a la vez; las frustraciones colocan al tribunal, al juez y a todos los incumbentes en una situación embarazosa».

Si nos remitimos al estudio sobre la incidencia de las causas en materia familiar en el Perú, en la jurisdicción de los niños y adolescentes, y otras de orden propiamente familiar, sólo a nivel de Lima Metropolitana tenemos la siguiente referencia:

* Eusebio Goutreaux, Dora: "El proceso familiar y sus características». 
Causas civiles ingresadas en los diez Juzgados de los Niños y Adolescentes, de enero a junio de 1994

\begin{tabular}{lr} 
Adopciones & 67 \\
Alimentos & 3563 \\
Bienes y enajenación & \\
(de bienes de menores) & 170 \\
Tenencia y custodia de menores & 450 \\
Guarda de menores & 40 \\
Patria potestad, pérdida, suspensión & 120 \\
Tutoría & 20 \\
Régimen de visitas & 240 \\
Consejo de Familia & 20 \\
& 4690 \\
TOTAL & \\
PROYECCIÓN POR UN AÑO, & \\
APROXMADAMENTE & 9380 \\
\hline
\end{tabular}

En los Juzgados Especializados, las causas en materia familiar tienen la siguiente distribución:

\begin{tabular}{lcc}
\hline & 1994 & 1995 \\
\hline ConTENCIOSAS & & \\
$\begin{array}{l}\text { Separación convencional } \\
\text { Separación y divorcio }\end{array}$ & 1961 & 2604 \\
$\begin{array}{l}\text { (causal) } \\
\text { Interdicción } \\
\begin{array}{l}\text { Alimentos } \\
\text { (mayores de edad) }\end{array}\end{array}$ & 1536 & 1403 \\
No conTENCIOSAS & 179 & 190 \\
$\begin{array}{l}\text { Patrimonio familiar } \\
\text { Adopciones } \\
\text { (mayores) }\end{array}$ & 112 & 00 \\
\hline
\end{tabular}


En consecuencia, también resulta conveniente que se tomen en cuenta las cifras enunciadas respecto a la carga procesal familiar, para los efectos de poder contar con normas procedimentales propias, como ya las tienen otros códigos, como el de Familia para el estado de Hidalgo (México) y que fue promulgado por decreto 130 de 1983 , expedido por el gobernador constitucional de dicho estado, exponiendo en uno de sus considerandos que: «se hace indispensable otro código, de Procedimientos Familiares, para el estado de Hidalgo, a fin de cohonestar la ley sustantiva con la adjetiva, independizando este procedimiento del civil, dándole fisonomía y efectividad propias, de las instituciones interesadas, y derechos familiares». Y en la exposición de motivos se agrega: «Arrancarle a los procedimientos civiles la verdadera valoración de los intereses familiares, que deben ser tutelados por el Derecho, es uno de los objetivos del Derecho procesal familiar. La creación en México de los juzgados familiares y las salas correspondientes en 1971, señaló el cambio para la protección integral de los valores familiares."

El Código de Familia de Panamá (promulgado por ley 3 de 17 de mayo de 1994 y vigente desde el 3 de enero de 1995) contiene normas procesales en el libro IV, con el título «De la jurisdicción y de los procedimientos".

Últimamente en Lima, Perú, felizmente se vienen dando avances muy positivos, primero, con la inclusión de varias instituciones de Familia en el Código de los Niños y Adolescentes, y, segundo, con la conversión de los diez Juzgados de los Niños y Adolescentes en Juzgados de Familia, por resolución administrativa 025-CME-PJ, por cuanto ya existe una sala respectiva de familia. Ahora bien, para ser efectivo, el procedimiento familiar debe ser unificado con el de los niños y adolescentes, por cuanto siendo su sujeto prevaleciente el niño y adolescente, no puede ser atendido de manera aislado ni independiente de su medio familiar.

\section{Normatividad procesal actual sobre familia en el Perú}

Sólo con carácter didáctico, presentamos un análisis esquemático de las reglas de procedimientos para cada tema de orden familiar, tanto de los que contiene el Código Civil, como el Código de los Niños y Adolescentes.

Para este efecto tenemos en consideración fundamentalmente las disposiciones del Código Procesal Civil, promulgado mediante decreto legislativo 768 de fecha 29 de febrero de 1992, y vigente desde el 28 de julio de 1993, que no solamente ha modificado sino también ha aclarado un gran número de las disposiciones del Código Civil, como hiciera 
notar el doctor Jorge Carrión Lugo', en un trabajo que presentara en el primer Congreso Nacional de Derecho Civil y Comercial organizado por la Universidad Nacional Mayor de San Marcos (Facultad de Derecho), en noviembre de 1994, en el que se afirma "que el Código Civil ha sido modificado y aclarado por el Código Procesal Civil en un gran número de sus disposiciones, tanto en el orden conceptual como en el orden procesal, señalando en este último caso los trámites que se deben observar para cada tipo de pretensión procesal que se apoya en el Código Civil; sin embargo, el Código Civil en varios de sus artículos también ha sido derogado por leyes especiales, por el Código de los Niños y Adolescentes y por la vigente Constitución de 1993".

\subsection{Temas e instituciones del Derecho familiar contenidos en el Código Civil, y su medio procedimental}

\subsubsection{Esponsales}

La acción a que se refiere la segunda parte del artículo 240 del Código Civil, derivada del incumplimiento de los esponsales, se tramita según el monto que se pretende. Así, se tramitará en el proceso de conocimiento si la estimación patrimonial del petitorio es mayor de 300 Unidades de Referencia Procesal (URP), en aplicación del inciso segundo del artículo 475 del Código Procesal Civil (CPC). En cambio, será tramitada en proceso abreviado la pretensión cuyo petitorio tenga una estimación patrimonial mayor de 20 y hasta 300 URP, como se establece en el inciso 7 del artículo 486 del CPC, y en proceso sumarísimo aquella cuya estimación patrimonial no sea mayor de 20 URP. El cálculo de la Unidad de Referencia Procesal para 1996 es de 220 nuevos soles, conforme se establece en la resolución administrativa del titular del pliego del Poder Judicial 047-96-Set-TP-CMP/PJ- de 7 de febrero de 1996, publicada en el diario oficial El Peruano el 8 del mismo mes y año, de donde se puede inferir el siguiente cuadro para los casos de indemnización por incumplimiento de esponsales:

\footnotetext{
" Carrión Lugo, Jorge: "Modificaciones al Código Civil por el Código Procesal Civil", ponencia presentada en el I Congreso Nacional de Derecho Civil y Comercial.
} 
Proceso de conocimiento

Proceso abreviado

Proceso sumarisimo
Monto mayor a 300 URP: más de S/. 66000,00

Monto mayor a 20 URP: más de S/. 4400,00 hasta S/. 66000,00

Monto no mayor a 20 URP: menos de $S / .4400,00$

\subsubsection{Impedimentos matrimoniales, licencia para matrimonio de menores y dispensa judicial de presentación de documentos}

En cuanto a la dispensa de la edad para matrimonio de menores: inciso 1 del artículo 241 del CC.

En cuanto a la dispensa del parentesco: inciso 2 del artículo $242 \mathrm{del}$ CC.

En cuanto a la licencia supletoria para matrimonio de menores, a falta de abuelos y abuelas o si éstos son absolutamente incapaces o han sido removidos de la tutela, corresponde al juez del niño y adolescente otorgar o negar la licencia: artículo 244, cuarto párrafo, del CC.

En cuanto a la dispensa judicial de presentación de documentos: artículo 249 del CC.

Todas estas acciones se adecuan al proceso no contencioso, conforme se establece en la sexta disposición complementaria del CPC.

\subsubsection{Oposición al matrimonio por impedimentos (art. $253 \mathrm{del}$ CC)}

Previamente se debe tomar en cuenta que si en estos casos se trata de matrimonios de niños y adolescentes, se adecuarán a la legislación pertınente.

Si la oposición matrimonial se basa en causa legal y los pretendientes niegan su existencia, el alcalde los remitirá al juez. Este caso corresponde al juez de paz letrado ante quien se debía celebrar el matrimonio, conforme se establece en el artículo 256 del CC. La oposición se tramitará como proceso sumarísimo, según las disposiciones complementarias del CPC. 
En cambio, la indemnización a que hubiere lugar en los casos de oposición injustificada o maliciosa se tramitará según el monto de la pretensión reclamada (caso similar de los esponsales).

\subsubsection{Prueba del matrimonio}

Se refiere, sin lugar a dudas, a la prueba de la existencia jurídica del matrimonio, situación distinta al cuestionamiento de su validez. En nuestra legislación no existe acción expresa para acreditar la existencia jurídica del matrimonio, como existe en otras legislaciones de manera formal, o mediante un trámite de afirmación sumaria, como en el caso de la legislación argentina. Así se desprende del análisis que hacen Gustavo A. Bussert y Eduardo Zannoni ${ }^{10}$, al comentar el artículo 197 del Código Civil argentino, indicando que, probada la imposibilidad, el hecho constitutivo de la prueba supletoria será la celebración del matrimonio. En el mismo trámite de la información sumaria se prueba la imposibilidad y la celebración del matrimonio.

En el caso del Perú, los artículos 269 y 270 del CC señalan:

Artículo 269.- [Prueba del matrimonio.-] Para reclamar los efectos civiles del matrimonio debe presentarse copia certificada de la partida del registro del estado civil.

La posesión constante del estado de matrimonio, conforme a la partida, subsana cualquier defecto puramente formal de ésta.

Artículo 270.- [Pérdida de la partida.-] Comprobada la falta o pérdida del registro o del acta correspondiente, es admisible cualquier otro medio de prueba.

Sobre estos aspectos surgen las siguientes interrogantes: primero, cuándo y de qué forma se hace uso de la prueba supletoria de la posesión constante; segundo, de qué manera se comprueba la falta o pérdida del registro o del acta correspondiente, y tercero, quién evalúa la admisibilidad de cualquier otro medio de prueba. No existe una orientación procesal expresa; sin embargo, haciendo uso del método de interpretación sistemática, debe entenderse, a nuestro parecer, que todos estos actos están referidos a los trámites establecidos en el artículo 75 del CC, concordante con los artículos 269 y 270 ya referidos, con observancia de las reglas del

i" Bussert, Gustavo, y ZaNnoni, Eduardo: Manual de Derecho de familia. 
proceso no contencioso, como se establece en el inciso noveno del artículo 749 del CPC (se tramita en proceso no contencioso la inscripción y rectificación de partida, con arreglo a las disposiciones de los artículos 826 y siguientes, y corresponde conocer al Juzgado de Paz letrado, conforme al artículo 750 del CPC; salvo que exista oposición, en cuyo caso se adecuará al proceso de conocimiento).

Articulo 750.- [Competencia.-] Son competentes para conocer los procesos no contenciosos los Jueces Civiles y los de Paz Letrados.

En el proceso no contencioso es inaplicable la competencia por razón de turno.

La competencia de los Juzgados de Paz Letrados es exclusiva para los procesos de inscripción y rectificación de partida y para los que contienen en la solicitud una estimación patrimonial no mayor a cincuenta unidades de referencia procesal.

\subsubsection{Invalidez del matrimonio}

Las acciones de invalidez del matrimonio, ya sea sustentadas en las causales de nulidad o en las de anulabilidad, se tramitan mediante las reglas del proceso de conocimiento, como se establece en el artículo 281 del CC (modificado por el CPC).

Es necesario un comentario en lo que respecta a la confirmatoria que les asiste a los menores (adolescentes) cuyo matrimonio hubiera sido invalidado por dicha causa (invalidación que corresponde conocer al juez especializado, en un proceso de conocimiento). Sin embargo, la confirmación de dicho matrimonio cuando adolescentes hubiesen adquirido su mayoría de edad -se dice en el inciso primero del artículo 277 del CC (modificado por el CPC)-, se solicita al juez de paz letrado del lugar del domicilio conyugal y se tramita como proceso no contencioso. La resolución que aprueba la confirmatoria produce efectos retroactivos, lo cual quiere decir, primero, que el juez de paz letrado deja sin efecto una resolución del juez especializado, y segundo, que dicha resolución tiene efecto retroactivo, validando lo que el superior invalidó. Lo de la confirmatoria está bien a nuestro criterio, pero podría sugerirse que la misma procedería ante el mismo juez que declaró la invalidación, por cuestión de orden práctico y del principio de inmediación procesal, como mero trámite similar a la disolución del matrimonio que contempla el artículo 354 del CC. 


\subsubsection{Deberes y derechos que nacen del matrimonio}

En el artículo 289 del CC se establece que es deber de ambos cónyuges hacer vida en común en el domicilio conyugal. El juez puede suspender ese deber cuando su cumplimiento ponga en grave peligro la vida, la salud, o el honor de cualquiera de los cónyuges, o la actividad económica de la que depende el sostenimiento de la familia. No se menciona en ninguna norma expresa el procedimiento; así, se puede constatar que no existe referencia en las disposiciones complementarias ni en las modificatorias del CPC. Por esa razón inferimos que puede estar referido en el inciso 6 del artículo 546 del CPC, orientando su tramitación al proceso sumarísimo, por no tener una vía procedimental propia y ser inapreciable en dinero ese deber. Por la urgencia de la tutela jurisdiccional, la causa debería corresponder al juez de paz letrado del domicilio conyugal.

En cuanto al derecho de representación de la sociedad conyugal, el artículo 292 del CC ha sido modificado por el CPC, con lo cual si un cónyuge abusa de tal derecho el juez de paz letrado puede limitárselo en todo o en parte. La pretensión se tramita como proceso abreviado.

\subsubsection{Libertad de trabajo de los cónyuges}

El artículo 293 del CC regula la libertad de trabajo de los cónyuges, con asentimiento expreso o tácito del otro. Si éste lo negara el juez puede dar su autorización si lo justifica el interés de la familia. Este hecho se tramitará en la vía de proceso sumarísimo, conforme se establece en la quinta disposición final del CPC.

\subsubsection{Régimen patrimonial}

En el Perú se han establecido dos sistemas sobre el régimen patrimonial en el matrimonio: el de separación y el de la sociedad de gananciales. Los cónyuges pueden optar por uno u otro antes del matrimonio, o, después de éste, sustituir el régimen elegido por el alternativo. Si no lo eligieran o no hubiera acuerdo antes del matrimonio, supletoriamente rige la sociedad de gananciales. Sin embargo, si después del matrimonio no hay acuerdo para la sustitución, se recurre a la vía judicial, a petición de cualquiera de los cónyuges, para sustituir el régimen de sociedad de gananciales por el de separación en los casos a que se refiere el artículo 329 del CC. 
Así se dispone en el artículo 297 del mismo cuerpo de leyes. Este trámite judicial se sigue con las reglas del proceso abreviado, de acuerdo a lo que se dispone en la cuarta disposición final complementaria del CPC.

\subsubsection{Obligación de sostener el hogar bajo cualquier régimen (en} sociedad de gananciales o en el de separación patrimonial)

Artículo 300.- [Obligación de sostener el hogar bajo cualquier régimen.-] Cualquiera que sea el régimen en vigor, ambos cónyuges están obligados a contribuir al sostenimiento del hogar según sus respectivas posibilidades y rentas.

En caso necesario el juez reglará la contribución de cada uno.

El trámite será en proceso sumarísimo, conforme a la quinta disposición final complementaria del CPC.

\subsubsection{Bienes que conforman la sociedad de gananciales (propios de cada cónyuge y sociales: art. 301 del CC)}

La administración de los bienes propios corresponde a cada cónyuge y pueden disponer de ellos o gravarlos (sin llegar al ejercicio abusivo del derecho, no amparado por el artículo II del Título Preliminar del CC).

Procede la administración de los bienes propios por uno de los cónyuges, conforme se dispone en el artículo 305 del CC.

Artículo 305.- [Administración de bienes por uno de los cónyuges.-] Si uno de los cónyuges no contribuye con los frutos o productos de sus bienes propios al sostenimiento del hogar, el otro puede pedir que pasen a su administración, en todo o en parte. En este caso, está obligado a constituir hipoteca y, si carece de bienes propios, otra garantía, si es posible, según el prudente arbitrio del juez, por el valor de los bienes que reciba.

La vía procedimental será la del proceso sumarísimo, también establecida en la quinta disposición complementaria final del CPC.

El artículo 306 establece que uno de los cónyuges puede administrar los bienes propios del otro en todo o en parte, con el asentimiento del otro, con la obligación del administrador de devolverlos en cualquier momento al propietario. Dicho requerimiento puede hacerse extrajudicial (vía notarial, por ejemplo) o judicialmente, según la vía que se establezca para los procesos no contenciosos, con una solicitud para que, a pedido del 
interesado y por decisión del juez, dicho requerimiento carezca de contención, como se establece en el inciso 12 del artículo $749 \mathrm{del} \mathrm{CPC.}$

En cuanto a la responsabilidad por deudas personales del otro cónyuge, a que se refiere el artículo 308 del CC, éstas se pagarán con bienes propios del obligado, a menos que se pruebe que se contrajeron en provecho de la familia. Dicha probanza se producirá en el proceso que origina la obligación principal (cobro de la deuda personal). La misma regla se aplicará al caso de la responsabilidad extracontractual de uno de los cónyuges, en caso de perjuicio del otro (art. 309 del CC).

\subsubsection{Acciones pertinentes para la calificación de los bienes que conforman la sociedad de gananciales (propios y sociales)}

Teniendo en cuenta la presunción que se establece en el inciso 1 del artículo 310 del CC, según el cual todos los bienes se presumen sociales, salvo prueba en contrario, se desprende que puede accionarse para la determinación de bien propio por parte del cónyuge que alega tal pretensión (usualmente el concepto empleado es el de calificación de bien propio).

La vía procedimental se establecerá teniendo en cuenta la cuantía de dichos bienes.

\subsubsection{Administración del patrimonio social}

Artículo 313.- [Administración del patrimonio social.-] Corresponde a ambos cónyuges la administración del patrimonio social. Sin embargo, cualquiera de ellos puede facultar al otro para que asuma exclusivamente dicha administración respecto de todos o de algunos de los bienes. En este caso, el cónyuge administrador indemnizará al otro por los daños y perjuicios que sufra a consecuencia de actos dolosos o culposos.

La indemnización a que se hace referencia será establecida en la vía procedimental que corresponda según la cuantía.

\subsubsection{Fenecimiento y liquidación de la sociedad de gananciales}

Producido el fenecimiento de la sociedad de gananciales por las causales que se establecen en el artículo 318 del CC, se procede a su liquidación en un proceso que es similar a una operación contable (con la acumulación del acrivo, la deducción del pasivo, con las deudas o cargas, y el establecimiento de las ganancias netas), y en donde la ganancia, en el caso 
de la sociedad de gananciales, recién se determina al final y toma el nombre de bienes gananciales, como se establece en el artículo 323 del CC.

Este proceso se inicia con el inventario valorizado de los bienes (art. 320 del CC). La facción de este inventario puede hacerse de manera convencional o judicial; en este último caso, la vía procedimental es la establecida para el proceso no contencioso, de acuerdo al artículo 749 del CPC.

\subsubsection{Liquidación de la sociedad de gananciales}

Si el fenecimiento de la sociedad de gananciales se produce por separación de cuerpos o divorcio (incs. 2 y 3 del art. 318 del CC), procede acumular la pretensión de separación de bienes gananciales en dicho proceso (art. 483 del CPC).

Procedería también dicha acumulación para los casos de invalidación del matrimonio (proceso de conocimiento), conforme se establece en el artículo 281 del CC.

Para los casos de fenecimiento de la sociedad de gananciales por las causales de declaración de ausencia, muerte de uno de los cónyuges o cambio de régimen patrimonial, no se señala una vía propia para proceder a la liquidación de dicha sociedad, por lo que no está prohibido que se utilice la vía procedimental de acuerdo a la cuantía de los bienes que conforman esa sociedad.

\subsubsection{Pérdida de los gananciales por uno de los cónyuges}

Sobre este tema existe una regla muy definida: cuando se trata (en nuestro sistema) del divorcio, el cónyuge culpable pierde el derecho de gananciales respecto de los bienes propios del otro (art. $352 \mathrm{del}$ CC). El trámite está sujeto a la forma de liquidación que se haga en el proceso de divorcio, o, en vía de acción, en el proceso de liquidación de la sociedad de gananciales señalado en el acápite anterior.

Sin embargo, como regla de carácter especial se contempla lo establecido en el artículo 324 del CC:

Artículo 324.- [Pérdida de gananciales por separación de hecho.-] En caso de separación de hecho, el cónyuge culpable pierde el derecho a gananciales proporcionalmente a la duración de la separación.

Esta situación particular está determinada sólo para el caso del abandono del hogar (separación de hecho), caso en que sí procede la pérdida 
de todos los bienes gananciales del culpable durante el tiempo del abandono. La acción estaría en su caso supeditada al proceso de divorcio, u otro en vía de acción directa (cuando no hay divorcio). La vía que corresponde dependería de la calificación que pueda hacer el juez o del monto de la pretensión.

\subsubsection{Uniones de hecho}

Para reclamar los efectos jurídicos que de manera restringida concede nuestra legislación a este tipo de uniones, resulta necesario previamente acreditar su reconocimiento. En el proceso respectivo se harán valer las acumulaciones necesarias y pertinentes que se conceden a los concubinos en el artículo 326 del CC (con las modificaciones tácitas de algunos aspectos que hace el art. 5 de la Constitución Política actual).

Esta acción debe tramitarse en la vía de conocimiento, en aplicación del inciso 1 del artículo 475 del CPC.

\subsubsection{Decaimiento y disolución del matrimonio}

Si se entiende por decaimiento la separación de cuerpos, debe considerarse que ésta procede de dos maneras. Una es por la forma convencional (antes: mutuo disenso), de acuerdo a las reglas del proceso sumarísimo, según se dispone en el inciso segundo del artículo 546 del CPC (con las reservas que tenemos: puede tratarse de un proceso no contencioso que no termina en divorcio - no se tramita- sino que éste se produce por disolución directa, conforme se establece en el artículo 354 del CC).

Pero, si se trata de la separación de cuerpos por causales, así como del divorcio (que sólo procede por causales: art. 333, menos el inc. 11, del $\mathrm{CC}$ ), entonces se tramitará como proceso de conocimiento, con las acumulaciones originarias de pretensiones, las sucesivas y las medidas cautelares, conforme se establece en el artículo 480 y siguientes del CPC.

\subsubsection{Sociedad paternofilial}

Las acciones derivadas de la filiación matrimonial, como la contestación del estado de filiación, o lo conocido también como impugnación de paternidad (que procede únicamente para la filiación matrimonial), conforme se establece en el artículo 363 del CC, así como también las acciones para la declaración judicial de la paternidad o maternidad extramatrimonial, se tramitan con las reglas del proceso de conocimien- 
to en aplicación del inciso 1 del artículo 475 del CPC. También corresponde a esta vía la acción que confiere el arrículo 399 del CC para los casos de impugnación al reconocimiento, en todas sus formas, de un hijo extramatrimonial.

\subsubsection{Acción alimentaria e indemnización de daño moral de la madre en los casos de declaración de paternidad extramatrimonial}

El artículo 414 del CC concede dichas acciones (de alimentar e indemnización) a la madre que ha tenido un hijo extramatrimonial y que ha obtenido la declaración de paternidad extramatrimonial en vía de reconocimiento o de manera judicial. Sin perjuicio de la acumulación originaria pertinente, con la acción de declaración judicial de paternidad podría accionarse de manera independiente mediante acción directa, en vía que dependerá de la cuantía, si se refiere a la indemnización (promesa de matrimonio: esponsales), o si se trata de alimentos se tramitará mediante el proceso sumarísimo ante el juez de paz letrado, por estar acreditada la obligación (con el reconocimiento o la sentencia declarativa de parernidad, en su caso), conforme se establece en el inciso primero del artículo 476 del CPC.

\subsubsection{Adopción}

El procedimiento establecido para la adopción está contenido en el artículo 379 del $\mathrm{CC}$, en el que se indica que ella se tramitará con arreglo al CPC (si se trata de adopciones de mayores de edad) o al Código de los Niños y Adolescentes (si se trata de adopciones de menores de edad). Esta norma concuerda con las disposiciones de los artículos 147 y siguientes del Código de los Niños y Adolescentes, complementadas con el artículo 152 del mismo código. El trámite, según este código, es el de proceso no contencioso, con declaración de abandono en investigación tutelar si se trata de niños o adolescentes en situación de abandono (art. 185). El trámite es de proceso no contencioso en Juzgado Especializado, según el CPC, si los adoptados son mayores (art. 749 CPC).

\subsubsection{Patria potestad y tutela}

Como principio fundamental, debe entenderse que la patria potestad (en sentido jurídico) está referida de manera inherente a una facultad de los padres con respecto a sus hijos menores de edad (menores de 18 
años), y que comprende derechos y deberes sobre la persona y bienes de estos hijos.

De lo anteriormente indicado se infiere que todos los trámites en los que se trate aspectos de niños y adolescentes se rigen por el Código de los Niños y Adolescentes, conforme se establece en los artículos IV y IX del mismo.

En consecuencia, en lo que respecta a la patria potestad, como regla su trámite debe estar referido al que se establece en el Código de los Niños y Adolescentes (así como también en lo que respecta a las demás instituciones que, según el libro tercero del mencionado código, se consideran como instituciones familiares bajo su alcance: patria potestad, suspensión, extinción, restitución, tenencia, régimen de visitas, alimentos, tutela y guarda, educación familiar y consejo de familia).

En lo que respecta a la patria potestad, deben tenerse en cuenta las acciones acumuladas al divorcio, como se ha indicado en dichos casos.

Sin embargo, hay que precisar que el Código Procesal Civil ha señalado para algunos aspectos relacionados con la patria potestad y su ejercicio, de igual forma que para la tutela y curatela, reglas específicas, que se tramitan como procesos no contenciosos conforme se establece en la primera disposición transitoria, así como en la sexta y séptima disposición final complementaria, que son las siguientes del Código Civil:

Artículo 419.- [Ejercicio conjunto de la patria potestad.-] La patria potestad se ejerce conjuntamente por el padre y la madre durante el matrimonio, correspondiendo a ambos la representación legal del hijo.

En caso de disentimiento, resuelve el juez del niño y adolescente conforme al proceso sumarísimo.

Artículo 426.- Los padres no están obligados a dar garantía para asegurar la responsabilidad de su administración, salvo que el juez, a pedido del consejo de familia, resuelva que la constituyan, por requerirlo el interés del hijo. En este caso, la garantía debe asegurar:

1) El importe de los bienes muebles.

2) Las rentas que durante un año rindieron los bienes.

3) Las utilidades que durante un año puede dejar cualquier empresa del menor.

Los incisos 2 y 3 sólo son de aplicación cuando los padres no tengan el usufructo de los bienes administrados. 
En lo que se refiere a la exoneración de los padres de prestar garantía, el juez puede resolver que ésta se constituya a pedido del consejo de familia, si lo requiere el interés del hijo.

Artículo 427.- [En los casos de exoneración de los padres a rendir cuentas periódicas, a no ser que el juez resuelva a solicitud del consejo de familia otra cosa.]

Artículo 428.- [En cuanto a la modificatoria de la garantía y rendición de cuenta de los padres (a que se refieren los arts. 426 y 427 del CC).]

Artículo 429.- [Referente a la celebración de convenios entre padres e hijos que lleguen a la mayoría de edad, salvo dispensa del juez.]

Artículo 433.- [Para el caso de nuevo matrimonio de padres, administradores de los bienes de sus hijos.]

Artículo 507.- [Referente a la tutela legal de los hijos extramatrimoniales de que trata el artículo 506 del CC.]

Según la quinta disposición final complementaria del CPC, se tramitarán en proceso sumarísimo las situaciones que se deriven de los siguientes casos del Código Civil:

Artículo 460.- [Cuando surja oposición de intereses entre padres e hijos se procederá al nombramiento de un curador especial.]

Artículo 468.- [Nombramiento judicial de curador en caso de que el consejo de familia no cumpla con lo dispuesto en el artículo 467 del CC (se refiere a los casos de los arts. 446, 463, 464 y 466 , inciso 3); el juez proveerá de un curador al hijo para que lo represente a éste en el juicio respectivo.]

También, conforme a lo dispuesto en la cuarta disposición final complementaria del CPC, se dispone que se tramitará en proceso abreviado lo que se derive de los siguientes casos del Código Civil:

Artículo 463.- [Las acciones que dan lugar a la privación de la patria potestad.] 
Artículo 465.- El juez puede autorizar a los hijos, por causas graves, para que vivan separados del padre o de la madre que hubiese contraído matrimonio, poniéndolos bajo el cuidado de otra persona.

El juez fija las atribuciones que ésta debe ejercer.

Articulo 471.- [En los casos de restitución de la patria potestad (sólo para quienes hayan sido privados de ella). En caso de suspensión será aplicable el artículo 85 del Código de los Niños y adolescentes.]

Artículo 539.- [Sobre la retribución económica del tutor.]

Como complemento de las disposiciones procedimentales referidas anteriormente, según su caso, también resulta conveniente aclarar que todos los actos a que se refieren algunos artículos del CC, a los que a continuación se hace referencia, se entiende que son de conocimiento del juez de los niños y adolescentes, según el procedimiento correspondiente que se establece en dicho código o el CPC. Los dispositivos aludidos del Código Civil son los siguientes:

Artículo 506.- [Cuando no hay tutor nombrado, la preferencia la decidirá el juez para designar uno.]

Artículo 508.- [Nombramiento de tutor dativo.-] A falta de tutor testamentario o escriturario y de tutor legítimo, el consejo de familia nombrará tutor dativo a una persona residente en el lugar del domicilio del menor.

El consejo de familia se reunirá por orden del juez o a pedido de los parientes, del Ministerio Público o de cualquier persona.

Artículo 512.- [Discernimiento del cargo de tutor.-] El tutor tiene la obligación de pedir el discernimiento del cargo. Si no lo hace, el juez debe ordenarlo de oficio, o a pedido de los parientes, del Ministerio Público o de cualquier persona.

Articulo 514.- [Medidas cautelares.-] Mientras no se nombre tutor o no se discierna la tutela, el juez, de oficio o a pedido del Ministerio Público, dictará todas las providencias que fueren necesarias para el cuidado de la persona y la seguridad de los bienes del menor. 
Artículo 516.- [Impugnación del cargo de tutor.-] Cualquier interesado y el Ministerio Público pueden impugnar el nombramiento de tutor efectuado con infracción del artículo 515 .

Si la impugnación precediera al discernimiento del cargo, se estará a lo dispuesto en el Código Procesal Civil.

Artículo 523.- [Autorización judicial para el retiro de dinero y valores.-] Los valores y el dinero a que se refieren los artículos 521 y 522 , no pueden ser retirados de las instituciones de crédito, sino mediante orden judicial.

Artículo 530.- El menor que ha cumplido catorce años y cualquier interesado puede recurrir al juez contra los actos del tutor.

Artículo 531.- [Autorización judicial para enajenación o gravamen de bienes.-] Los bienes del menor no pueden ser enajenados ni gravados sino con autorización judicial, concedida por necesidad o utilidad y con audiencia del consejo de familia. Se exceptúan de esta disposición los frutos en la medida que sean necesarios para la alimentación y educación del menor.

Artículo 532.- [Autorización judicial para otros actos que requiera el tutor.-] El tutor necesita también autorización judicial concedida previa audiencia del consejo de familia para:

1) Practicar los actos indicados en el artículo 448.

2) Hacer gastos extraordinarios en los predios.

3) Pagar deudas del menor, a menos que sean de pequeña cuantía.

4) Permitir al menor capaz de discernimiento, dedicarse a un trabajo, ocupación, industria u oficio [...].

5) Celebrar contrato de locación de servicios.

6) Celebrar contratos de seguro de vida o de renta vitalicia a título oneroso $[\ldots]$.

Artículo 533.- [Intervención del mayor de dieciséis años en los casos de los artículos 531 y 532.]

Artículo 534.- [Procedimiento para la autorización judicial: es de aplicación lo dispuesto en el artículo 449 (intervención del menor en disposición de sus bienes).] ta.]

Artículo 535.- [Venta de los bienes del menor fuera de subas- 
Artículo 536.- [Actos practicados por el tutor sin autorización judicial.]

Artículo 542.- [Forma de rendición de cuentas: proceso abreviado.-] La rendición, a solicitud del tutor o del consejo de familia, se presenta en ejecución de sentencia del proceso abreviado. La presentación, en audiencia que el juez señalará al efecto y con presencia del menor si tiene mas de catorce años, se hace por escrito, adjuntando copia de los documentos justificantes u ofreciendo otros medios probatorios. En la audiencia, el tutor proporcionará las explicaciones que le sean solicitadas.

La demanda de desaprobación se formula, de ser el caso, dentro del plazo de caducidad de sesenta días después de presentadas las cuentas y se tramita como proceso de conocimiento.

Artículo 554.- [Remoción del cargo de tutor.]

Artículo 555.- [Suspensión provisional del cargo de tutor.]

Artículo 557.- [El menor que ha cumplido catorce años puede pedir al juez la remoción del tutor.]

Articulo 563.- [Tutela oficiosa.]

\subsubsection{Alimentos}

El instituto del derecho alimentario también ha sido integrado al Código de los Niños y Adolescentes, conforme se establece en los artículos 101 y siguientes del referido cuerpo legal. Sin embargo, se entiende que sólo se aplicarán tales dispositivos cuando se trate de los alimentos para los niños y adolescentes (y, en caso excepcional, para una petición conjunta con la madre o hermanos mayores), como se establece en los artículos 105 y 106 del aludido cuerpo legal. Sin embargo, por disposición posterior al CPC, fue necesario expedir otra resolución permitiendo el conocimiento de dichos procesos también al Juzgado de Paz Letrado, en forma transitoria, mientras no se provea mayor número de Juzgados de los Niños y Adolescentes, hoy convertidos en Juzgados de Familia.

En cuanto al derecho de alimentos para hijos mayores de edad (arts. 473 y 483 del CC), así como para el caso del llamado hijo alimentista (art. 415 del CC), para el caso de concubinos (art. 326 del CC), de las madres solteras (reconocimiento o declaración judicial de los hijos 
extramatrimoniales, art. 414 del CC), de los excónyuges (art. 350 del $\mathrm{CC})$, la demanda se tramitará con arreglo al proceso sumarísimo, conforme se establece en el artículo $546 \mathrm{del} \mathrm{CPC.}$

\subsubsection{Curatela}

Hay que señalar, como se dispone en el artículo 565 del CC, que la curatela se instituye para:

1) Los incapaces mayores de edad.

2) La administración de bienes.

3) Asuntos determinados.

Según el artículo 566 del CC, no puede nombrarse curador para los incapaces sin que preceda declaración judicial de interdicción, salvo en el caso del inciso 8 del artículo 44 del CC (los que sufren pena que lleva anexa la interdicción civil).

La interdicción se rige por los trámites del proceso sumarísimo, como se establece en el inciso 3 del artículo 546 del CPC, y corresponde nombrar curador al juez que conoce la interdicción, conforme se establece en el artículo 581 del CC.

El curador de los incapaces a que se refieren los artículos 584 (declaración de prodigalidad), 585 (incapacidad por mala gestión) y 586 (curatela del ebrio habitual o toxicómano) será designado por el juez, oyendo al consejo de familia.

En cuanto a la curatela especial a que se refiere el artículo 606 del $\mathrm{CC}$, también se tramita en proceso sumarísimo, como se establece en la quinta disposición final complementaria del CPC.

\subsubsection{Consejo de familia}

Conforme se establece en el artículo 619 del CC, habrá un consejo de familia para velar por la persona e intereses de los menores y de los incapaces mayores de edad que no tengan padre ni madre. También lo habrá aunque viva el padre o la madre, en los casos que señala este código.

Por consiguiente, el trámite está determinado para cada caso, como se consigna en el artículo 622 del CC, que indica que el juez de menores o el de paz, en su caso, puede decretar la formación del consejo, de oficio o a pedido del Ministerio Público o de cualquier persona. 
Como conclusión a todo lo desarrollado en el acápite 3.1.11 y siguientes de este trabajo, se puede resumir que corresponde al juez de los niños $\mathrm{y}$ adolescentes el conocimiento de los siguientes procesos contenciosos (art. 184 del CNA):

1) Suspensión, extinción o restitución de la patria potestad.

2) Tenencia.

3) Régimen de visitas.

4) Tutela.

5) Alimentos.

6) Protección a los intereses difusos o individuales que le atañen.

El trámite es el establecido por el proceso único y, en forma supletoria, por las normas del CPC (art. 185 del CNA).

Los procesos no contenciosos que corresponde conocer al juez especializado del niño y adolescente, son (art. 186 del CNA):

1) De la guarda.

2) Del consejo de familia.

3) De la licencia para enajenar y utilizar bienes de menores.

4) De las autorizaciones (dispensa matrimonio, viajes.)

5) De la adopción.

6) Los demás que señale la ley.

En cuanto a los procesos que no tengan procedimiento especial contemplado en el Código de los Niños y adolescentes, se rigen por las normas del CPC. 